\title{
Role of the filler on Portland cement hydration at very early ages: Rheological behaviour of their fresh cement pastes
}

\author{
R. Talero ${ }^{\mathrm{a}, *}$, C. Pedrajas ${ }^{\mathrm{a}}$, M. González ${ }^{\mathrm{c}}$, C. Aramburo ${ }^{\mathrm{d}}$, A. Blázquez $^{\mathrm{a}}$, V. Rahhal ${ }^{\mathrm{b}}$ \\ a "Eduardo Torroja" Institute for Construction Sciences - CSIC, Calle Serrano Galvache n' 4, 28033 Madrid, Spain \\ ${ }^{b}$ Departamento de Ingenieria Civil Facultad de Ingenieria UNPCBA, Avda. del Valle 5737, Argentina, (B7400JW), Olavarría, Argentina \\ ${ }^{\mathrm{c}}$ Escuela Técnica Superior de Ingenieria de la Edificación - UPM, Avda. Juan de Herrera, 6, 28040 Madrid, Spain \\ d Cementos ARGOS, S.A., Laboratorio de Control Calidad, Carrera 19, \#12132, Yumbo, Valle del Cauca, Medellin, Colombia
}

\section{H I G H L I G H T S}

- The effects of $Q$ and $C$ fillers, on rheological behaviour of $P C$ at very early ages.

- Direct and non-direct stimulations of the PC hydration, consequence about plastic viscosity.

- Chemical interaction: Specific of $Q$ and $C$ fillers with portlandite and $C_{3} A$, respectively.

- Technical consequences in PC-Q or $C$ pastes: yield stress, shear stress and plastic viscosity.

Keywords:

Rheology

Portland cement

Fresh pastes

Fillers

Hydration stimulus

\begin{abstract}
A B S T R A C T
The rheological behaviour of fresh Portland cement (PC) pastes with different chemical and potential mineralogical compositions was analysed when were blended with crystalline mineral additions (fillers). These two fillers were very different: a siliceous, $Q \alpha$-quartz type, and another limestone, $C$. Trials were conducted during latent hydration at $25^{\circ} \mathrm{C}$. The findings showed that apparent viscosity was higher in the $\mathrm{PC}$ with low $\mathrm{C}_{3} \mathrm{~A}$ and high $\mathrm{C}_{3} \mathrm{~S}$ content, consequently, the $\mathrm{Na}_{2} \mathrm{O}_{\mathrm{eq}}(\%)$ content of everyone also contributed very significantly. Moreover, it was also observed that the incorporation of each filler affects differently the rheological behaviour of fresh cement pastes. The different influence is due to the different physical and chemical properties of each filler (nature, chemical composition and character and texture intimate of the particles), and also of the type of PC to interact. Finally and at these very early ages, both fillers stimulated the hydration of the PC which they were mixed by direct and non-direct way, and in the case of $C$ filler by indirect way as well, but without any pozzolanic activity. Despite the fact that blended cement P1/Q 60/40 has proved to be a "false positive" in Frattini test.
\end{abstract}

\section{Introduction}

Global warming, one of the symptoms of climate change, is regarded as a serious threat to the environment. Many scientific studies associate climate change with greenhouse gas emissions, of which $\mathrm{CO}_{2}$ is the primary component. In response to those concerns, the inclusion of crystalline mineral fillers as additions is standard practice in cement manufacture. In this vein:

- in 2005 the authors published an article entitled 'Early hydration of Portland cement with crystalline mineral additions' [1] and

\footnotetext{
* Corresponding author.

E-mail address: talero@ietcc.csic.es (R. Talero).
}

- in 2012 as second entitled 'Role of the filler on Portland cement hydration at early ages' [3].

In retrospect, some of the authors of those papers believe that, inasmuch as both focused on the early-age heat of hydration generated by Portland cement (PC) in the presence of absence of finely ground crystalline mineral additions such as $\alpha$-quartz $\left(\alpha-\mathrm{SiO}_{2}\right)$ or calcite [1] and on the type of physical and chemical interactions between the PC and each type of filler [3], their titles were overly ambitious. Neither actually encompassed all the actually takes place in PC early-age hydration, from the very instant when its particles and the filler particles come into contact with the mixing water.

Conduction calorimetry tests were run on the same two PCs chosen for this study, with or without the two mineral additions mentioned at the replacement ratios specified. The trials were 
begun on fresh paste and terminated after $48 \mathrm{~h}$ [1]. The parameters monitored during the tests were absolute and relative total heat released and heat released at significant ages, such as hydration latency [1-5] and a number of other ages. In calorimetric studies of cement pastes, the heat release rate is high during the solution period primarily as a result of initial hydrolysis. Thereafter the rate drops to a minimum constituting the first nadir on the calorimetric curve. This is followed by acceleration of the hydration reactions and mass precipitation of reaction products, primarily CSH gel. The heat release rate at the second peak representing the mass hydration of tricalcium silicate and the third peak, representing the transformation of ettringite into hydrated calcium monosulphoaluminate. These parameters were monitored irrespective of the fact that:

- some of the heat of hydration values were released by the fresh paste, i.e., while still in a fluid state;

- other amounts were released in a pseudo-fluid state (after setting had commenced), and

- the rest of the heat, through the end of the $48 \mathrm{~h}$ test, was released after the specimens hardened (long after setting had come to an end).

Consequently, further to the titles of the two articles [1,3], one at least should have included information on the fresh paste rheology. Including such findings would have rendered the paper unfit for publication, however, for it would have been too lengthy. That is why the authors wish to publish those findings hereunder.

As shown in the aforementioned studies and other calorimetric research conducted [1-6], the effect of mineral additions the length of the latency period and on the properties of the paste up to that age depends on whether the filler is crystalline [1-4] or otherwise [5], the type of Portland cement and the replacement ratio. Moreover, despite their crystallinity, these mineral additions interact physically and may interact chemically with Portland cement [3]. For those reasons, both prior studies [1,3] determined the type of physical and chemical interaction that took place between the Portland cement and the siliceous and the limestone filler. Whilst an early-age hydration mechanism was also described, the ages addressed were not as early as in this new endeavour: prior to fresh paste setting.

The filler $<>$ Portland cement paste interaction has a heavy impact not only on the heat released in early-age cement [1-6], but also on the rheological behaviour of the resulting fresh paste. One of the major rheological properties is viscosity, of considerable significance for concrete or mortar mixing, shipping, pouring and on-site casting, as well as their workability and consolidation. This parameter is particularly important in self-consolidating or mechanically pumped concrete and mortar.

Viscosity may be assessed with rheometric trials to determine, for instance, shear stress or stress $(\sigma)$ by varying the rotational speed. Stress also depends on the type of PC, type of mineral addition and replacement ratio, as well as on the temperature, water: cement ratio and the acceleration/deceleration cycles applied. The resulting flow curves provide a measure of fluidity.

In light of those considerations, a number of tests were conducted to analyse the effect of fillers and the type of variables that impact fresh paste viscosity during the latency period, in particular with respect to the timing of rheological behaviour. The findings were also applied to determine the most appropriate type of cycle to be used for each fresh paste. Suitability was defined in terms of the area of the hysteresis loop characteristic of the thixotropic behaviour of fresh pastes [7-10] (the larger the better) and the response observed in the Portland cements with different potential mineralogical compositions [11]. The best results were analysed and the rheological behaviour of the fresh Portland cement pastes studied after the inclusion of apparently inert (i.e., non-pozzolanic) fillers with variable origin, chemical composition, mineralogy, geology and particle size, shape and intimate texture.

The two types of mineral additions filler type consisted in the excess generated during crushed aggregate grinding. The effect of these fillers on fresh Portland cement paste rheology was ascertained by using two very different mineral additions: one siliceous in nature and acid in chemical character, $\left(\alpha-\mathrm{SiO}_{2}\right), \mathrm{Q}$ and the other calcareous in nature and basic in chemical character, $C$, i.e., with different chemical compositions, types of crystallinity, geochemical origin, nature, chemical character, particle size, shape and intimate texture. Both were ground to approximately cement fineness.

\section{Materials and methodology}

\subsection{Selection of materials and preliminary tests}

Two Portland cements (PC) with widely different potential mineralogical compositions were chosen to ensure that the results would be extensive to any type of PC. The first one, denominated PC1 and characterized by its high $\mathrm{C}_{3} \mathrm{~A}(\%)$ content, whose mineralogical composition was found to be followed: $51.0 \% \mathrm{C}_{3} \mathrm{~S}, 16.5 \% \mathrm{C}_{2} \mathrm{~S}$, $14.0 \% \mathrm{C}_{3} \mathrm{~A}$ and $5.5 \% \mathrm{C}_{4} \mathrm{AF}$, a density of 3.08 , a Blaine specific surface, BSS, of $319 \mathrm{~m}^{2} / \mathrm{kg}$ and a loss on ignition of $1.6 \%$ and $\mathrm{Na}_{2} \mathrm{Oeq}$. of $1.24 \%(>0,6 \%)$. On the other hand, the second Portland cement, $\mathrm{PC} 2$, was selected due to its low $\mathrm{C}_{3} \mathrm{~A}(\%)$ and high $\mathrm{C}_{3} \mathrm{~S}(\%)$ contents; its detail mineralogical composition was: $79.5 \% \mathrm{C}_{3} \mathrm{~S}, 2.5 \% \mathrm{C}_{2} \mathrm{~S}$ $\approx 0.0 \% \mathrm{C}_{3} \mathrm{~A}(<1.0 \%)$ and $10.0 \% \mathrm{C}_{4} \mathrm{AF}$, a density of 3.21 , a BSS of $329 \mathrm{~m}^{2} / \mathrm{kg}$ and a loss on ignition of $1.1 \%$ and $\mathrm{Na}_{2} \mathrm{Oeq}$. of $0.56 \%(<0,6 \%)$. Finally, the crystalline minera additions (i.e. non-pozzolanic) chosen as fillers $[12,13]$ were as follows:

- a quartz one, Q (ground ASTM C 778-92a sand [14]), with a $\mathrm{SiO}_{2}$ content of over $99 \%$, a density of 2.70 , a BSS of $395 \mathrm{~m}^{2} / \mathrm{kg}$ and a loss on ignition of $0 \%$, being therefore additionally, siliceous in nature and acid in chemical character; and the other,

- a limestone one, $C$ (ground Spanish limestone routinely used to manufacture cement concretes, and mortars) with a $\mathrm{CaCO}_{3}$ content of over $95 \%$, a density of 2.71, a BSS of $362 \mathrm{~m}^{2} / \mathrm{kg}$ and a loss on ignition of $42.5 \%$, being therefore additionally, calcareous in nature and basic in chemical character.

Both fillers were ground to a size which $\leq 20 \%$ of the material passed through a No. 325 sieve in a wet sieving process (mesh size $45 \mu \mathrm{m}$ ) [15]. Further to lase diffraction test findings (Fig. 1), after grinding, the two fillers exhibited similar fineness. They were also analysed with XRD to verify their crystallinity (Figs. 2 and 3 )

Finally and in order to examine the moisture absorption or adsorptivity of both fillers, the equal amounts of $\approx 1.0 \mathrm{~g}$ of the each $(C$ and $Q$ ) was separately placed in porcelain vials and then stored in a desiccator (with water distilled at bottom -instead of silica gel- to guarantee the $\mathrm{RH} \geq 95 \%$ conditions). The experiment was carried out at $23 \pm 1.7^{\circ} \mathrm{C}$ and the findings are present in Table 2. Thus, their adsorptivity values were also determined and found to be approximately $65 \%$ lower in $Q$ than in $C$. The explanation for that difference is discussed in reference [1].

The replacement ratios used were 20 and $40 \%$ for both fillers $Q$ and C, all by Portland cement mass. So, blended cements used in the survey were batched in a proportion of $80 / 20$ and $60 / 40$, Portland cement (\%)/filler (\%). The $100 / 00$ ratio denotes a pure Portland cement. The water demand for normal consistency and initial and final setting times determined in accordance with EN 196-3 standard [16] for the cements studied are given in Table 1.

Also on the other hand, all pure and blended cements mentioned were analysed by testing Frattini [17], although it wasn't applicable for any of them. According to Spanish cement code RC-16 [12] and European standard EN 197-1 [13], the Frattini test is required of pozzolanic cements only. Although none of the pure or blended cements used in this study was pozzolanic, all were tested with this procedure in the understanding that the respective findings would help explain their rheological behaviour.

In the Frattini test for every blended cements, the calcium hydroxide content in the aqueous solution in contact with the hydrated sample kept at $40^{\circ} \mathrm{C}$ for first hydration hours (20 and $60 \mathrm{~min}$, first nadir and second peak of conduction calorimetric findings, one and two days) was compared to the solubility isotherm for calcium hydroxide in an alkaline solution kept at the same temperature. The mineral addition is regarded to produce pozzolanic activity (=positive result) when the calcium hydroxide concentration in the sample solution was below the solubility isotherm curve, but as both PC are plain, i.e., both of them had not any pozzolan amount, the $[\mathrm{CaO}]$ and $\left[\mathrm{OH}^{-}\right]$contents of their respective liquid phase have to be in contrast, necessarily over the solubility isotherm curve for calcium hydroxide in alkali solution (=negative result).

It is necessary to say that initial and final setting times were determined according to EN 196-3 [16] standard and first nadir and second peak of conduction calorimetric findings times were determined in a previous research [23]. 

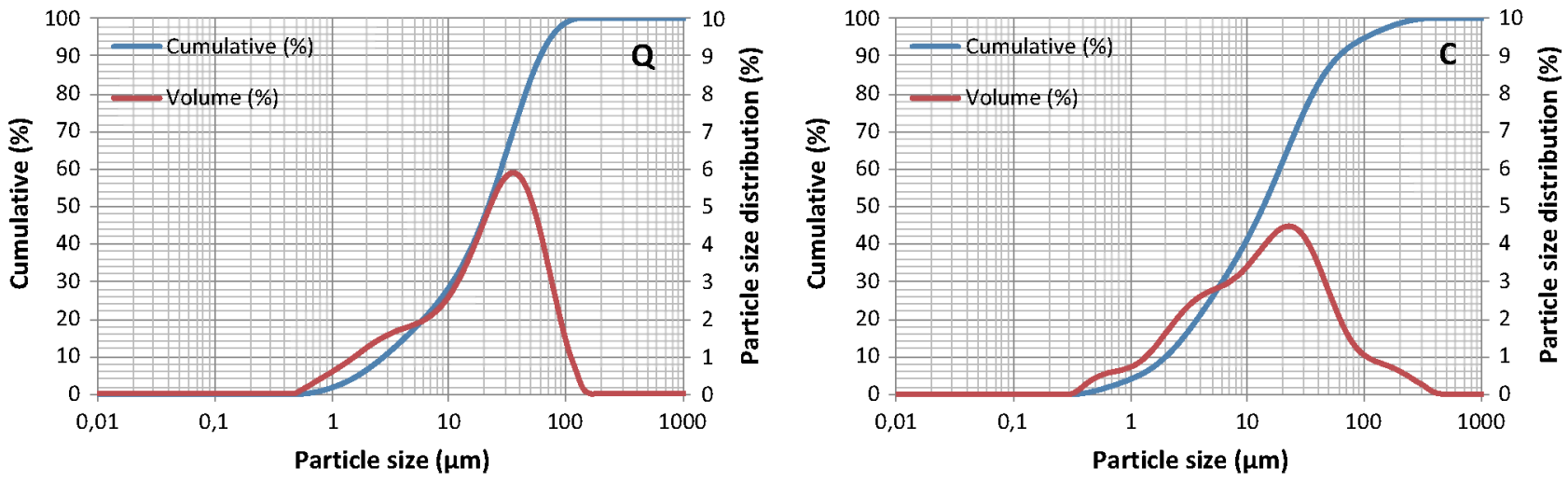

Fig. 1. Particle size distribution for fillers $Q$ and $C$ (laser granulometry findings).

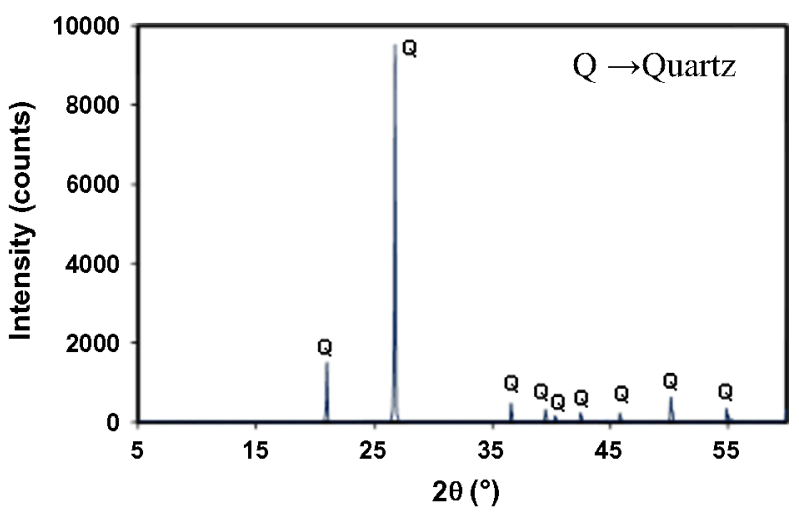

Fig. 2. XRD pattern for filler Q.

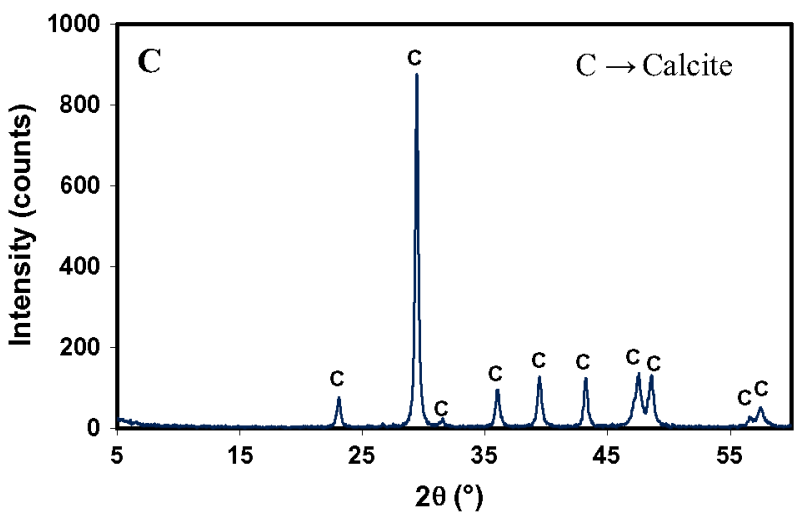

Fig. 3. XRD pattern for filler $C$.

\subsection{Rheological tests}

The rheological trials were conducted on a rotational rheometer fitted with a profiled rotor blade with serrated surface (internal diameter $\left(R_{i}\right)=19.010 \mathrm{~mm}$; height $(h)=55 \mathrm{~mm}$ ), a profiled cylinder, a temperature control unit for coaxial cylinders and a circulation thermostat. After analysing the effect of varying the aforementioned parameters, a scheme was designed with 10 -s intervals, three velocities and down ramping preceeding up ramping which made the evolution of cement pastes become the biggest hysteresis loop (thixotropic behaviour). The Doherty-Hurd method was proposed which is based in a reconstructiondestruction of the structure. A continuous variation of shear rate between a maximum and minimum value was applied, assuming at the maximum, the structure is close to destroyed and at the minimum is not rebuilt [18]. So, this control shear rate test $(\mathrm{CR})$ proposed gave an extra information about the specific behaviour of each fresh cement paste as a result of the mineralogical composition of Portland cement and the physical state and chemical composition of the additions used.
A control shear rate test (or CR test) was chosen for every case. The scheme designed (Fig. 4) was as follows: $10^{\prime \prime}$ from 0 to $45 \mathrm{rad} / \mathrm{s}$ [ $\mathrm{A}_{1}$ point]; $30^{\prime \prime}$ at $45 \mathrm{rad} / \mathrm{s}$ $\left[\mathrm{A}_{2}\right.$ point $] ; 10^{\prime \prime}$ from 45 to $27 \mathrm{rad} / \mathrm{s} ; 10^{\prime \prime}$ at $9 \mathrm{rad} / \mathrm{s} ; 10^{\prime \prime}$ from 9 to $0 \mathrm{rad} / \mathrm{s}$ [ $\mathrm{C}_{1}$ point]; $10^{\prime \prime}$ rest $\left[C_{2}\right.$ point $] ; 10^{\prime \prime}$ from 0 to $9 \mathrm{rad} / \mathrm{s} ; 10$ " from 9 to $27 \mathrm{rad} / \mathrm{s} ; 10^{\prime \prime}$ at $27 \mathrm{rad} / \mathrm{s} ; 10^{\prime \prime}$ from 27 to $45 \mathrm{rad} / \mathrm{s}$ [ $\mathrm{A}_{2}$ point]; $30^{\prime \prime}$ at $45 \mathrm{rad} / \mathrm{s}$ [B $\mathrm{B}_{2}$ point] and $10^{\prime \prime}$ from 45 to $0 \mathrm{rad} / \mathrm{s}$ $\left[\mathrm{C}_{3}\right.$ point]. Trials were conducted during latent hydration at $25^{\circ} \mathrm{C}$ because the viscosity of these materials is strongly dependent on the shear rate applied and on the degree of hydration of the cement paste, so this experimental scheme minimizes the different cement hydration rate influence $[7-11,19]$.

Fig. 4 shows the cycle applied to each fresh paste. Points $A_{1}, B_{1}, C_{1}, C_{2}, A_{2}, B_{2}$ and $C_{3}$ obtained from each curve are labelled on the graph. Yield stress $\left(\sigma_{0}\right)$ parameter values were determinated too, but these shear stress points were chosen to try to find the best way to explain the dynamic behaviour of cement pastes and predict the mixing and application processes. In fact, the yield stress values were also adjusted with the model thay provides a better regression, in this case was Casson equation (Eq. (1)) $[8,18,19]$.

$\tau=\left[\tau_{0}+\left(\eta_{p} \cdot \dot{\gamma}\right)^{1 / 2}\right]^{2}$

For the rheometric trials, the samples were hydrated at a water:binder (cement + filler) ratio $(\mathrm{w} / \mathrm{b})$ of 0.5 in every case. The fresh pastes were mixed manually for $2 \mathrm{~min}$ in a porcelain capsule, were stored in water bath at $25^{\circ} \mathrm{C}$ until they were tested and poured into the viscometer annulus. Test times were made to concur with the hydration latency period. The latency period was determined with prior calorimetric trials [1-5]. X-ray dif fraction was applied to identify the hydrated and unhydrated compounds present in the resulting pastes, likewise during hydration latency.

The effect of the two fillers, Q and C, on the two Portland cements, PC1 and PC2, was also analysed by determining the zeta potential of each fresh paste from initial hydration through setting on a Malvern Instruments ZETASIZER 2000, in light of the direct relationship between that parameter and fresh cement paste viscosity [20]. Fresh paste rheological behaviour clearly depends upon the colloidal stability of the system. In this test, when the scatter from a laser beam focused on a sample is recorded, the data are used to calculate the zeta potential of the doublelayered particles. In this study the sample was an aqueous solution in contact with the fresh paste during hydration at $25^{\circ} \mathrm{C}$. The zeta potential was determined for the pastes at a total of seven ages: at $20 \mathrm{~min}, 60 \mathrm{~min}$ and $120 \mathrm{~min}$, at the outset and end of setting and at the first nadir and second peak on their calorimetric curve [1-5].

\section{Results and discussion}

\subsection{Preliminary tests}

Table 1 gives the key physical characteristics of the two Portland cements studied, with and without each of the two fillers, $Q$ and $\mathrm{C}$, namely water demand for a normal consistency and initial and end setting times.

First of all, the presence of both fillers have produced a accelerating effect on the setting times of both PC1 and PC2, (except PC2/ Q samples, (Table 1)). This phenomenon was favoured with the presence of filler $\mathrm{C}$ and Portland cement PC1. Such observed influences are related to the different inner texture of these materials (the $C$ filler texture is very granulated and with very submicroscopic and microscopic particles as a result of its geochemical 
Table 1

Physical characteristics of PC1 and PC2 with and without filler Q or C.

\begin{tabular}{|c|c|c|c|c|c|}
\hline \multirow[t]{2}{*}{ Physical parameter } & \multicolumn{5}{|l|}{ Cement } \\
\hline & PC1 100/00 & PC1/Q 80/20 & $\mathrm{PC} 1 / \mathrm{Q} 60 / 40$ & PC1/C $80 / 20$ & $\mathrm{PC} 1 / \mathrm{C} 60 / 40$ \\
\hline Water demand $\left(\mathrm{w} / \mathrm{c}^{2}\right)$ & 0.31 & 0.32 & 0.32 & 0.33 & 0,33 \\
\hline Initial setting (h:min) & $3: 20$ & $2: 45$ & $3: 15$ & $1: 00$ & $0: 50$ \\
\hline Final setting (h:min) & $5: 10$ & $4: 30$ & $4: 45$ & $2: 15$ & $2: 10$ \\
\hline \multirow[t]{2}{*}{ Physical parameter } & \multicolumn{5}{|l|}{ Cement } \\
\hline & PC2 100/00 & $\mathrm{PC} / \mathrm{Q} 80 / 20$ & $\mathrm{PC} 2 / \mathrm{Q} 60 / 40$ & $\mathrm{PC} 2 / \mathrm{C} 80 / 20$ & $\mathrm{PC} 2 / \mathrm{C} 60 / 40$ \\
\hline Water demand $\left(\mathrm{w} / \mathrm{c}^{2}\right)$ & 0.28 & 0.29 & 0.30 & 0.30 & 0.29 \\
\hline Initial setting (h:min) & $4: 30$ & $5: 05$ & $5: 00$ & $2: 55$ & $2: 40$ \\
\hline Final setting (h:min) & $6: 15$ & $7: 00$ & $8: 00$ & $4: 35$ & $4: 40$ \\
\hline
\end{tabular}

${ }^{1}$ Water needed for normal consistency; ${ }^{2} \mathrm{w} / \mathrm{c}=$ water cement ratio.

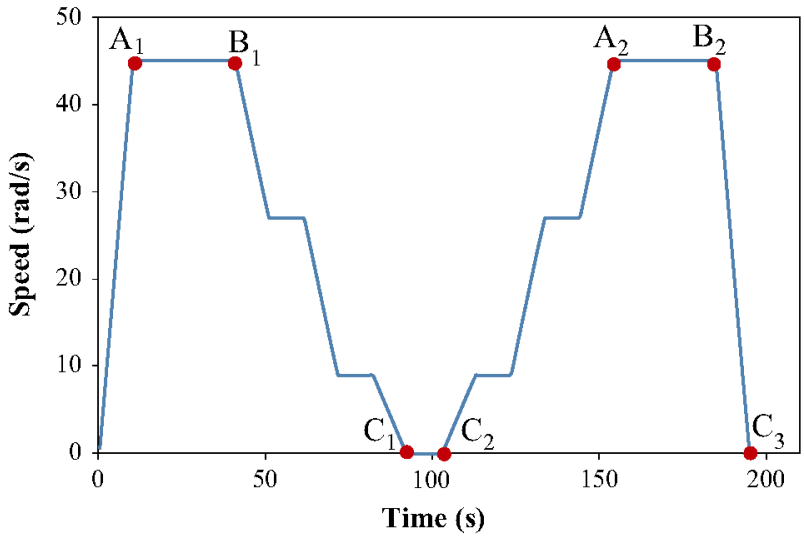

Fig. 4. Proposed scheme for CR test.

origin [21,22] and it is not totally compact like for $Q$ filler and, therefore, improves the moisture absorption capacity of $C$ filler which is higher than it occurs for Q filler). This phenomenon was confirmed by lab tests (Table 2). In addition, it justifies the better behaviour as an inner moist closed, which finds reflection in its water for normal consistency (Table 1) and the water needed for its storage values. Hence, the set of its $\mathrm{PC}$ is as easier as faster, where its $\mathrm{C}_{3} \mathrm{~A}(\%)$ is always more receptive than its corresponding $\mathrm{C}_{3} \mathrm{~S}(\%)$ content.

The higher shortening of the setting times has once again been provoked by the stimulation effect of the corresponding $\mathrm{PC}$ fraction hydration by both, fillers $Q$ and $C$, by direct $[1,23]$ and non-direct [3] stimulation. These stimulation hydration phenomenon's are more intense in $C_{3} A$ phase than $C_{3} S$ phase and, as a consequence, greater reduction of the PC setting times. Further proof lies in the observation that the BSS $\left(362 \mathrm{~m}^{2} / \mathrm{kg}\right)$ of $\mathrm{C}$ filler is nonetheless lower than the BSS $\left(395 \mathrm{~m}^{2} / \mathrm{kg}\right)$ of Q filler.

As expected, $\mathrm{PC} 1$ had a higher water demand than $\mathrm{PC} 2$, given its greater capacity to form sulfoaluminates and calcium aluminate hydrates, which have substantial amounts of chemically combined water. On the other hand, the setting times for PC1 were also shorter than for $\mathrm{PC} 2$, in keeping with its high $\mathrm{C}_{3} \mathrm{~A}$ content $(14 \%)$, which should exhibit greater fresh paste shear stress at the later stages of the rheological trial, although not in the earliest ages because of its higher $\mathrm{Na}_{2}$ Oeq.: 1.24 and $0.56 \%$, respectively [11].

In the same way, the water demand for normal consistency remained practically unaltered in both cements after $Q$ filler was added. That may be due, in part, to the low moisture in quartz (Table 2) as well as to its lack of pozzolanic or hydraulic activity. Even though for PC1/Q 60/40 blended cement, the first point of Frattini test at the age of $20 \mathrm{~min}$, strangely developed a positive result in its pozzolanic activity. Therefore, the following questions arise: What is the reason that the $Q$ filler has shown pozzolanic characteristics at the age of 20 minutes, because it isn't a pozzolan?. According to the previous question, the pozzolanic activity shown by the filler $Q$ at the age of 20 minutes Is it real or fictitious?. In this case and according to the chemical-physical characteristics of the filler $Q$ whose nature is siliceous, acid in chemical character and with compact intimate texture, it behaves like an inhibitor of PC1 hydration at that early age by provoking a phenomenon of electrostatic repulsion between filler particles and the dipolar ones of mixing water. Therefore, it had to prevent that the particles of PC1 began to hydrate from the first moment. To this phenomenon would have to add the effect of physical dilution that its replacement by $\mathrm{PC} 1$ causes. Therefore, blended cement $\mathrm{P} 1 / \mathrm{Q}$ $60 / 40$ has given a "false positive" result at the age of 20 minutes, whereas filler $C$ hasn't given it, because it is calcareous in nature, basic in chemical character and it has a granular texture. This is one of the causes but there may be more that are being investigated at this time that complete the knowledge of this phenomenon. However, the setting times changed depending on the percentage of Portland cement replaced. In PC1 both the initial and final times were shortened, while both were lengthened in $\mathrm{PC} 2$. The former was indisputably due to direct $[1,23]$ and non-direct [3] hydration stimulation by $\mathrm{Q}$ filler and the considerable $C_{3} A$ content in the PC1 fraction in the blend, as well as to the respective $C_{3} S$ content, although to a much lesser extent. That setting times in $\mathrm{PC} 2$ (with a high $\mathrm{C}_{3} \mathrm{~S}$ content $-79 \%$ - and nil $\mathrm{C}_{3} \mathrm{~A}$ content) were retarded more with rising replacement ratios (see Table 1) was proof of the physical dilution effect induced.

As shown in earlier studies, in the cement pastes containing $C$ filler, direct stimulation induced greater and faster hydration in $\mathrm{C}_{3} \mathrm{~A}$ than in the majority clinker phase $\mathrm{C}_{3} \mathrm{~S}$. Unsurprisingly, then, the blended cements prepared with $\mathrm{PC} 1$ (with $14 \% \mathrm{C}_{3} \mathrm{~A}$ ) exhibited

Table 2

Humidity absorption for fillers $Q$ and $C$.

\begin{tabular}{|c|c|c|c|c|c|c|}
\hline \multirow[t]{2}{*}{ Crystalline Mineral Additions (fillers) } & \multicolumn{6}{|c|}{$\begin{array}{l}\text { Humidity Absorption (\%) } \\
\text { Age (days) }\end{array}$} \\
\hline & 1 & 3 & 7 & 14 & 21 & 28 \\
\hline $\mathrm{Q}$ & 0.41 & 0.49 & 1.38 & 1.76 & 2.75 & 2.75 \\
\hline$C$ & 2.07 & 2.53 & 3.35 & 3.90 & 6.67 & 6.67 \\
\hline
\end{tabular}


earlier initial and end setting times, given the stimulation of hydration in its $C_{3} A$ fraction. Such stimulation would be:

- direct [1,23], prompted by the mixing water that differentially moistened the particles of the fillers $Q$ and $C$;

- and non-direct [3], prompted by the zeta potential generated as hydration progressed.

Hence, the particles of the two fillers ultimately behaved like nucleation or precipitation sites, respectively, for the calcium hydroxide with which their respective liquid phases were supersaturated.

At the same time, stimulation would also be indirect in filler $\mathrm{C}$ [24], albeit with no pozzolanic activity, for its $\mathrm{CaCO}_{3}$ was wholly crystalline and basic in chemical character [3]. Under those circumstances, the calcium carbonate would be able to react with the $\mathrm{C}_{3} \mathrm{~A}$ to form calcium tri- and mono-carboaluminate hydrate and especially calcium hemi-carboaluminate hydrate. Nonetheless, calcium mono-carboaluminate would be favoured to the detriment of the AFm forming at the outset of the hydration of the cement in the blend, in turn converted into slow-forming ettringite or ett-If [25].

When fillers $Q$ and $C$ partially replaced $\mathrm{PC} 1$ in the respective blends, the $\mathrm{pH}$ of the liquid phase of the resulting pastes (tested with the Frattini test at $25^{\circ} \mathrm{C}$ [17]) declined as the replacement ratio rose. That finding attested to the physical dilution effect and hence of the $\mathrm{Na}_{2} \mathrm{Oeq} \%$ content in PC1 and the portlandite generated after initial hydration. As a result, the $\left[\mathrm{OH}^{-}\right]$decreased in its liquid phase at all the Frattini test ages in all but blended cement PC1/C $80 / 20$. In that cement, direct [1,23], non-direct [3] and indirect stimulation of hydration (albeit in the absence of pozzolanic activity [24]) induced by the $C$ calcareous filler fraction prevailed in the clinker over the dilution effect observed for all the other blends. The same pattern was observed and for the same reasons in the fluctuations in [CaO], which declined at $120 \mathrm{~min}$ and the second peak on its calorimetric curve [1] in all cases with the exception once again of blended cement PC1/C 80/20 (see Fig. 5).

In contrast, when $\mathrm{PC} 2$ was partially replaced by the fillers (Fig. 5), medium basicity rose in the early hydration reactions, a development that was intensified with rising replacement ratios. At longer test ages, however, the liquid phase in all the blended

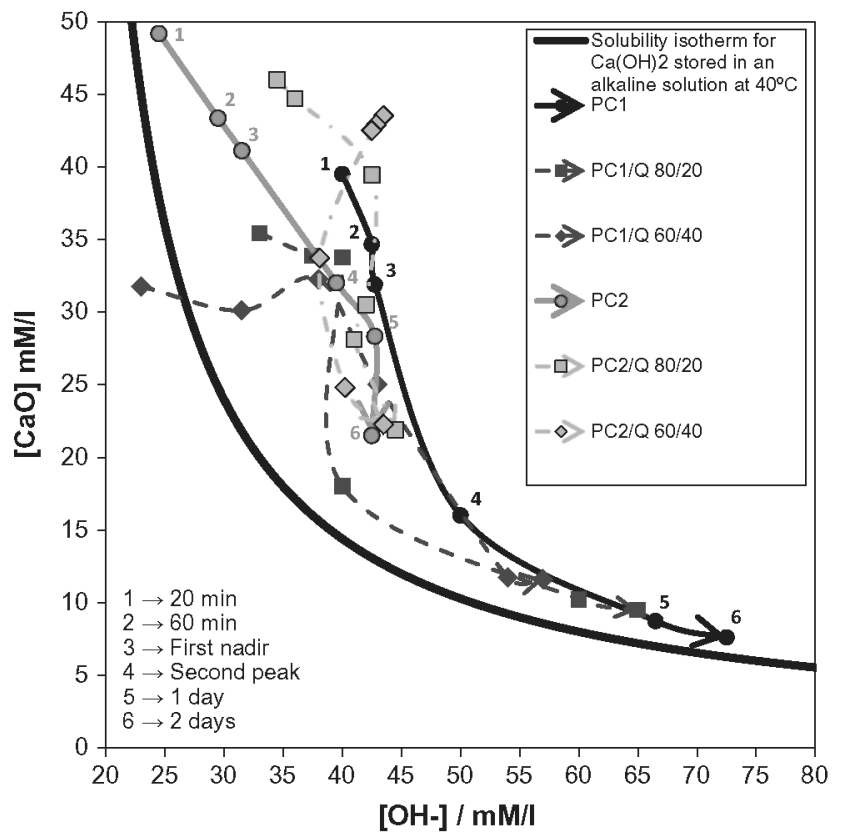

cements was less alkaline than the respective pure Portland cement. That finding inferred that both fillers stimulated Portland cement hydration more effectively when the $C_{3} A$ content was high than when $C_{3} S$ was high. Therefore, of the two PC phases, $C_{3} A$ was more logically prone to greater and faster hydration stimulation.

\subsection{Rheological tests}

Figs. 6 and 8 plot the yield stress against the shear applied (CR test) to the fresh pastes made with pure Portland PC1 and its blends with fillers $Q$ and $C$, whereas Figs. 7 and 9 graph the same parameters for the fresh pastes made with pure PC2 and its blends with the two fillers.

The singular points shown in Fig. 4 were identified for all the rheological tests. The fresh paste values for the $\mathrm{PC} 1$ and its family of blended cements are given in Table 3 and for PC2 and its family in Table 4. These Tables also include a column showing the age (or latent period) of each paste when tested, along with a column with the $\mathrm{pH}$ of the liquid phase found with the Frattini test [17], conducted at $25^{\circ} \mathrm{C}$. The Casson $[8,18,19]$ rheological model was used to determine the yield stress for each fresh cement paste.

\subsubsection{Comparative study of $P C 1$ and $P C 2$}

After $120 \mathrm{~min}$ of hydration, fresh paste $\mathrm{PC} 1$ reached a shear stress at point $A_{1}$, i.e., after the first $10 \mathrm{~s}$ of rotation at $45 \mathrm{rad} / \mathrm{s}$, of $91.91 \mathrm{~Pa}$. At point $\mathrm{B}_{1}$, after 30 " of constant rotation, stress decreased sharply, to nearly $38 \mathrm{~Pa}$ [(91.91-54.07) Pa] (thixotropic behaviour). When the rotor blade was stopped (point $C_{1}$ ), the shear stress remaining in the paste was $11.48 \mathrm{~Pa}$. After a 10 second pause, the paste recovered part of its shear stress (point $\mathrm{C}_{2}$ ), which rose to $12.30 \mathrm{~Pa}$. Nonetheless, the particles in the fresh paste and its liquid phase must not have been the same at point $\mathrm{C}_{2}$ as when the fresh paste was placed in the rheometer. Rather, new hydration products must have formed, particularly from $\mathrm{C}_{4} \mathrm{AF}$ and $\mathrm{C}_{3} \mathrm{~A}$ origin specially (calcium aluminate hydrates) and from $\mathrm{C}_{2} \mathrm{~S}$ and $\mathrm{C}_{3} \mathrm{~S}$ origin (calcium silicate hydrate ( $\mathrm{CSH}$ ) gels, in addition to the portlandite in the liquid phase up to the supersaturation level, see Fig. 5).

The resulting viscosity sufficed to lower shear stress by approximately $50 \%$ when the fresh paste was subjected to the same

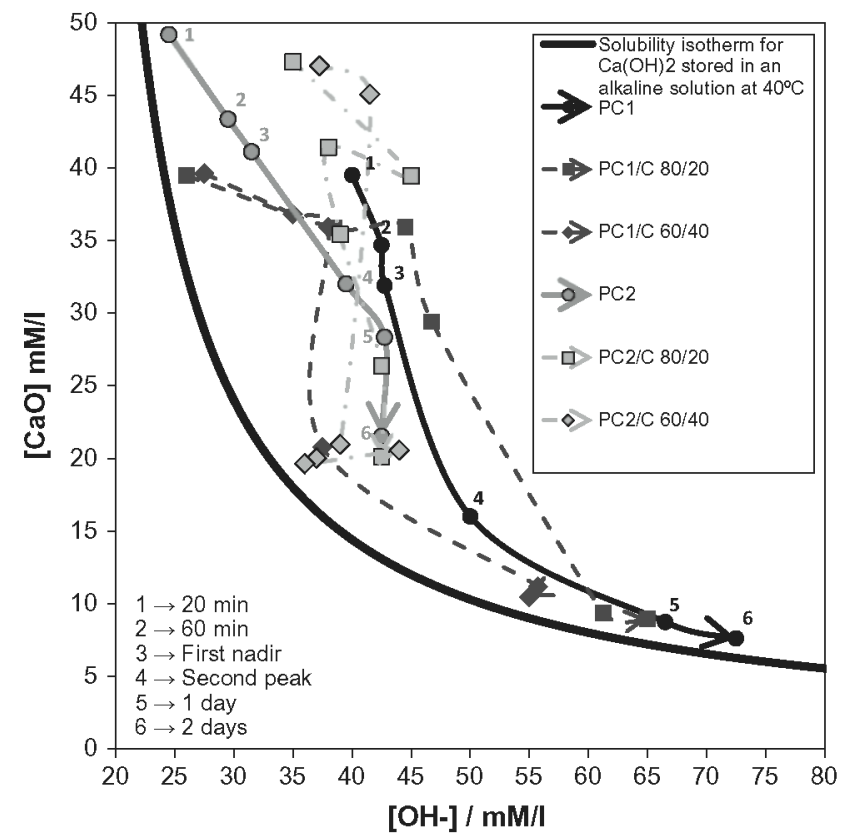

Fig. 5. Frattini test results for $P C 1$ and $P C 2$ with and without filler $Q$ or $C$. 


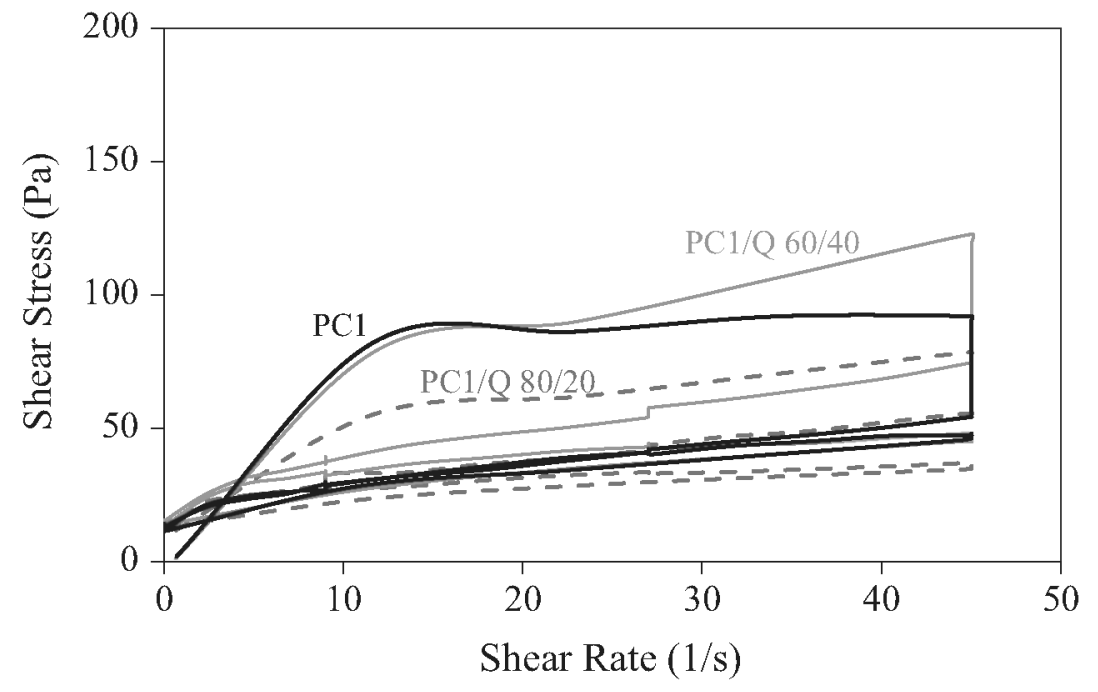

Fig. 6. Rheological behaviour of fresh PC1 paste with and without filler Q.

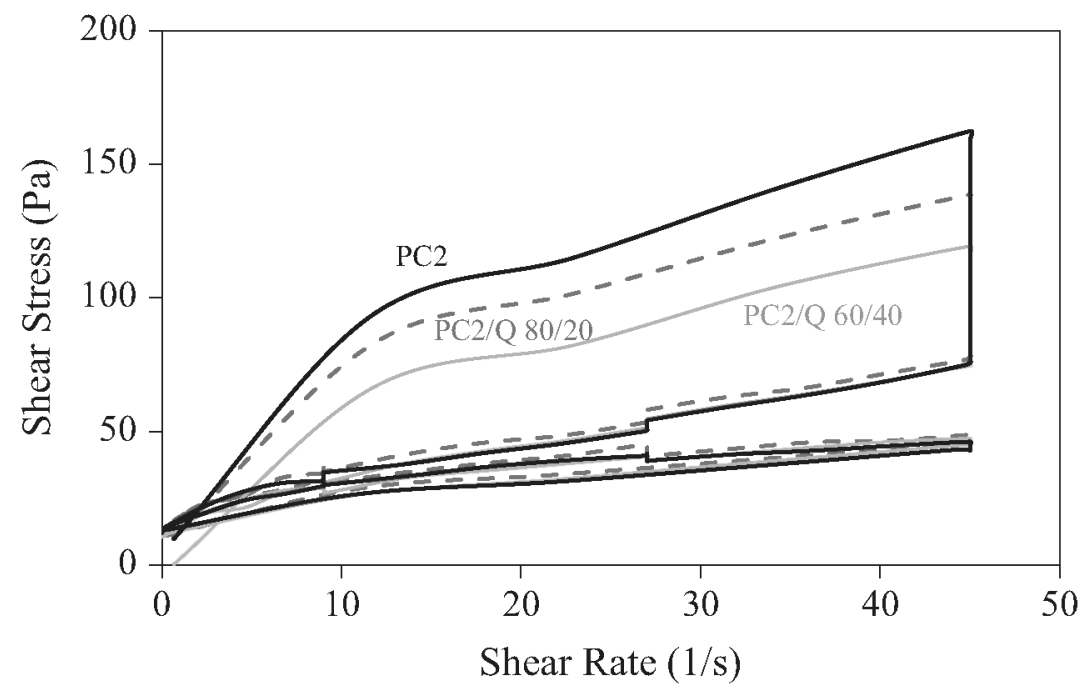

Fig. 7. Rheological behaviour of fresh $\mathrm{PC} 2$ paste with and without filler $\mathrm{Q}$.

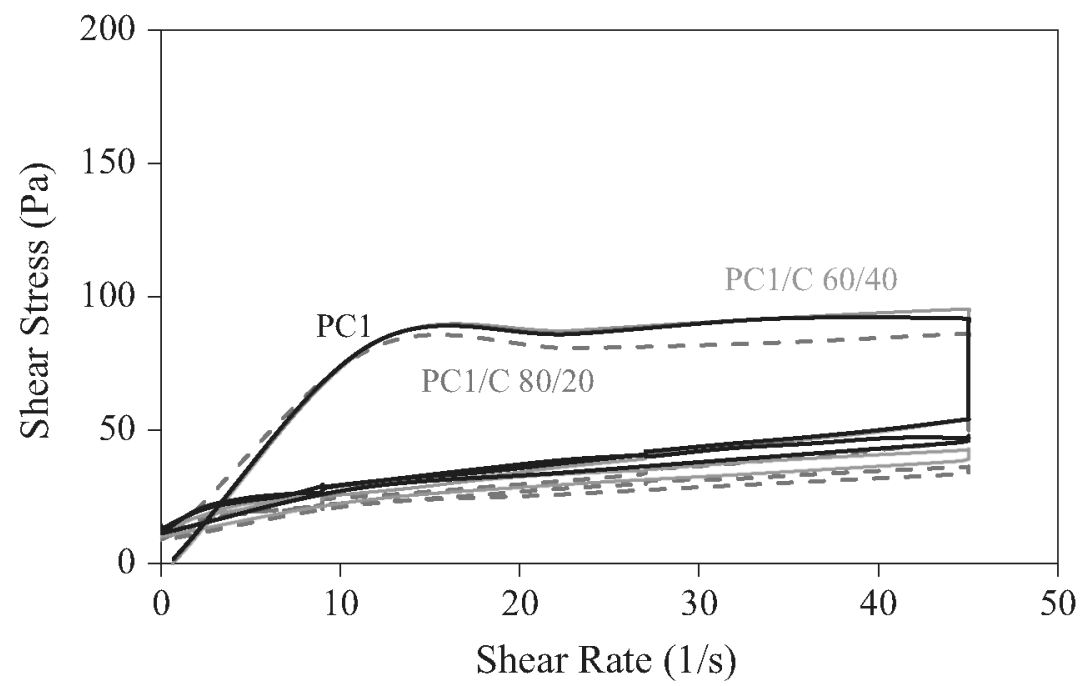

Fig. 8. Rheological behaviour of fresh PC1 paste with and without filler C. 


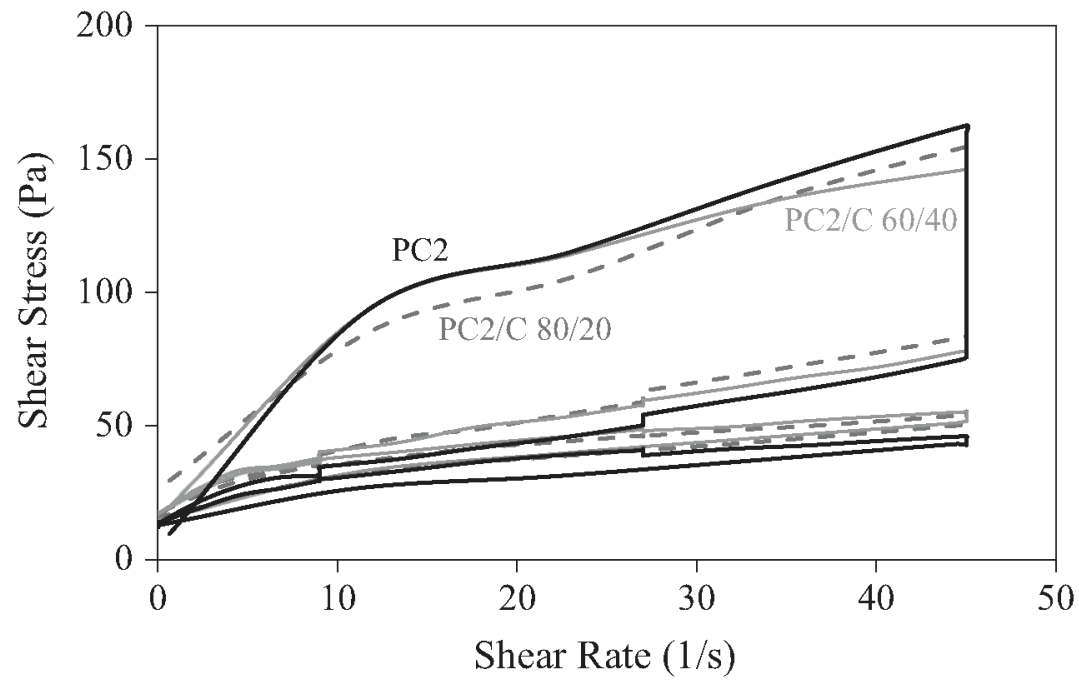

Fig. 9. Rheological behaviour of fresh PC2 paste with and without filler C.

Table 3

CR test results for fresh PC1 pastes with and without filler Q or C.

\begin{tabular}{|c|c|c|c|c|c|c|c|c|c|c|c|}
\hline \multirow[t]{2}{*}{ Cement } & \multirow[t]{2}{*}{$\mathrm{pH}^{*}$} & \multirow[t]{2}{*}{$\mathrm{w} / \mathrm{c}$ ratio $^{2^{*}}$} & \multirow[t]{2}{*}{$\operatorname{Age}^{3^{*}}(\mathrm{~min})$} & \multirow[t]{2}{*}{$\tau_{0}(\mathrm{~Pa})$} & \multicolumn{7}{|c|}{ Shear stress values for $\mathrm{PC} 1$ with and without filler $\mathrm{Q}$ or $\mathrm{C}(\mathrm{Pa})$} \\
\hline & & & & & $\mathrm{A}_{1}$ & $\mathrm{~B}_{1}$ & $C_{1}$ & $C_{2}$ & $\mathrm{~A}_{2}$ & $\mathrm{~B}_{2}$ & $C_{3}$ \\
\hline PC1 $100 / 00$ & 12.38 & 0.50 & 120 & 71.98 & 91.91 & 54.07 & 11.48 & 12.30 & 47.20 & 46.15 & 11.35 \\
\hline $\mathrm{PC} 1 / \mathrm{Q} 80 / 20$ & 12.18 & 0.50 & 100 & 34.34 & 78.50 & 55.34 & 12.81 & 13.90 & 36.97 & 34.77 & 12.76 \\
\hline PC1/Q 60/40 & 11.98 & 0.50 & 125 & 41.42 & 122.70 & 74.48 & 15.09 & 13.60 & 48.06 & 44.98 & 13.75 \\
\hline $\mathrm{PC} 1 / \mathrm{C} 80 / 20$ & 12.28 & 0.50 & 50 & 74.54 & 86.21 & 46.01 & 9.102 & 9.526 & 36.34 & 34.21 & 8.682 \\
\hline PC1/C $60 / 40$ & 12.29 & 0.50 & 80 & 69.54 & 95.47 & 53.50 & 11.79 & 13.52 & 42.68 & 39.23 & 10.19 \\
\hline
\end{tabular}

"Liquid phase during latent period as per the Frattini test [15] at $25^{\circ} \mathrm{C}$; ${ }^{2 *}$ water:cement ratio; ${ }^{3 *}$ duration of latent period as per conduction calorimetry [1].

Table 4

$\mathrm{CR}$ test results for fresh $\mathrm{PC} 2$ pastes with and without filler $\mathrm{Q}$ or $\mathrm{C}$.

\begin{tabular}{|c|c|c|c|c|c|c|c|c|c|c|c|}
\hline \multirow[t]{2}{*}{ Cement } & \multirow[t]{2}{*}{$\mathrm{pH}^{*}$} & \multirow[t]{2}{*}{ w/c ratio ${ }^{2^{*}}$} & \multirow[t]{2}{*}{$\operatorname{Age}^{3^{*}}(\min )$} & \multirow[t]{2}{*}{$\tau_{0}(\mathrm{~Pa})$} & \multicolumn{7}{|c|}{ Shear stress values for $\mathrm{PC} 2$ with and without filler $\mathrm{Q}$ or $\mathrm{C}(\mathrm{Pa})$} \\
\hline & & & & & $\mathrm{A}_{1}$ & $\mathrm{~B}_{1}$ & $C_{1}$ & $C_{2}$ & $\mathrm{~A}_{2}$ & $\mathrm{~B}_{2}$ & $C_{3}$ \\
\hline PC2 $100 / 00$ & 12.35 & 0.50 & 100 & 40.32 & 162.50 & 75.78 & 13.44 & 12.04 & 46.15 & 42.87 & 12.83 \\
\hline $\mathrm{PC} 2 / \mathrm{Q} 80 / 20$ & 12.37 & 0.50 & 180 & 38.93 & 138.70 & 77.92 & 12.99 & 12.77 & 48.77 & 45.19 & 10.58 \\
\hline $\mathrm{PC} 2 / \mathrm{Q} 60 / 40$ & 12.24 & 0.50 & 95 & 26.10 & 119.40 & 74.46 & 11.19 & 11.30 & 47.37 & 44.77 & 11.36 \\
\hline $\mathrm{PC} 2 / \mathrm{C} 80 / 20$ & 12.31 & 0.50 & 80 & 33.20 & 154.60 & 83.73 & 16.23 & 16.14 & 54.14 & 50.48 & 15.90 \\
\hline $\mathrm{PC} 2 / \mathrm{C} 60 / 40$ & 12.31 & 0.50 & 95 & 31.33 & 146.10 & 77.95 & 17.27 & 17.10 & 55.30 & 51.83 & 14.69 \\
\hline
\end{tabular}

"Liquid phase during latent period as per the Frattini test [15] at $25^{\circ} \mathrm{C}$; ${ }^{2 *}$ water:cement ratio; ${ }^{3 *}$ duration of latent period as per conduction calorimetry [1].

controlled rate of $45 \mathrm{rad} / \mathrm{s}$ at point $A_{2}$, while subsequently, at point $B_{2}$ where the stimulus was the same as at $B_{1}$, stress dipped by a mere $15 \%$. Lastly, at the end of the test, i.e., at point $C_{3}$, the remaining shear was similar to the value recorded at point $C_{1}$. The foregoing showed, in short, the high degree of thixotropic recovery in fresh paste PC1.

In fresh PC2 paste, after 100 min of hydration, the shear stress at point $A_{1}$ (after the first $10 \mathrm{~s}$ of the rheological trial, when the rotational speed was $45 \mathrm{rad} / \mathrm{s}$ ) came to $162.5 \mathrm{~Pa}$. In this case, the shear stress was much higher than in PC1, due firstly to the lower $\mathrm{Na}_{2}$ Oeq. content $(0.56$ compared to $1.24 \%)[7,11]$ and hence lower liquid phase $\mathrm{pH}$ : 12.35 compared to 12.38 , as shown in Tables 3 and 4 , respectively.

And this in spite of that the proportions of usual and less usual hydration products (especially slow-forming ettringite, ett-lf, with its hexagonal prismatic needles and rosettes [25,26,27] and alumina, ferric oxide, mono-sulfate, AFm with its hexagonal plates) generated must have varied widely between the two Portland cements because their potential mineral composition likewise differed (see diffractograms in Figs. 10 and 11). Similarly, after fresh PC2 paste was rotated at a constant rate up to point $B_{1}$, its shear stress decreased by nearly $87 \mathrm{~Pa}$ (thixotropic behaviour).

In both PC1 and PC2, shear stress decreased by around one half of the value reached at points $A_{1}$. But the rest of findings for the two fresh pastes can be summarised as follows. Firstly, at point $\mathrm{C}_{1}$, the shear stress remaining in fresh $\mathrm{PC} 2$ paste was $13.44 \mathrm{~Pa}$, although with a clear tendency to decrease over time, slipping to $12.04 \mathrm{~Pa}$ at point $\mathrm{C}_{2}$. Under the same circumstances, the shear stress in fresh $P C 1$ paste rose from $11.48 \mathrm{~Pa}$ at point $C_{1}$ to $12.30 \mathrm{~Pa}$ at point $C_{2}$. Secondly, at point $A_{2}$ the shear stress of the fresh paste PC2 was approximately only one quarter lower than at point $A_{1}$, while in fresh $P C 1$ paste the shear stress at $A_{2}$ was around half of the $A_{1}$ value. Thirdly, at point $B_{2}$, where the stimulus was the same as at point $B_{1}$, the shear stress in fresh $P C 2$ paste dropped by $45 \%$, whereas in fresh PC1 paste stress decreased by a mere $15 \%$. 


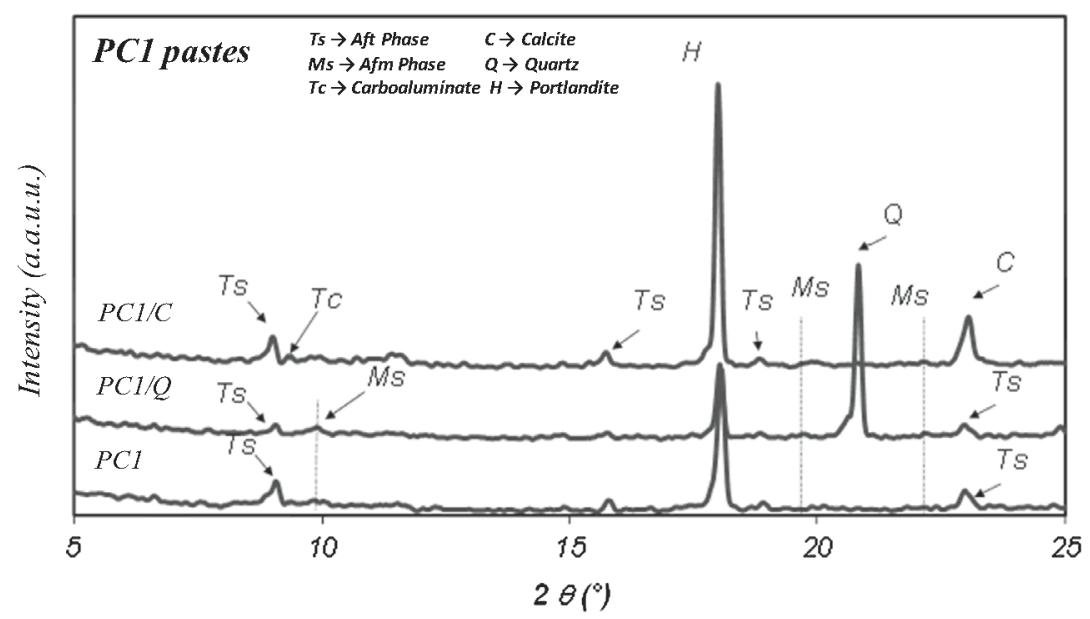

Fig. 10. XRD patterns for fresh PC1 pastes with and without fillerQ or C (60/40), during the latent period of hydration.

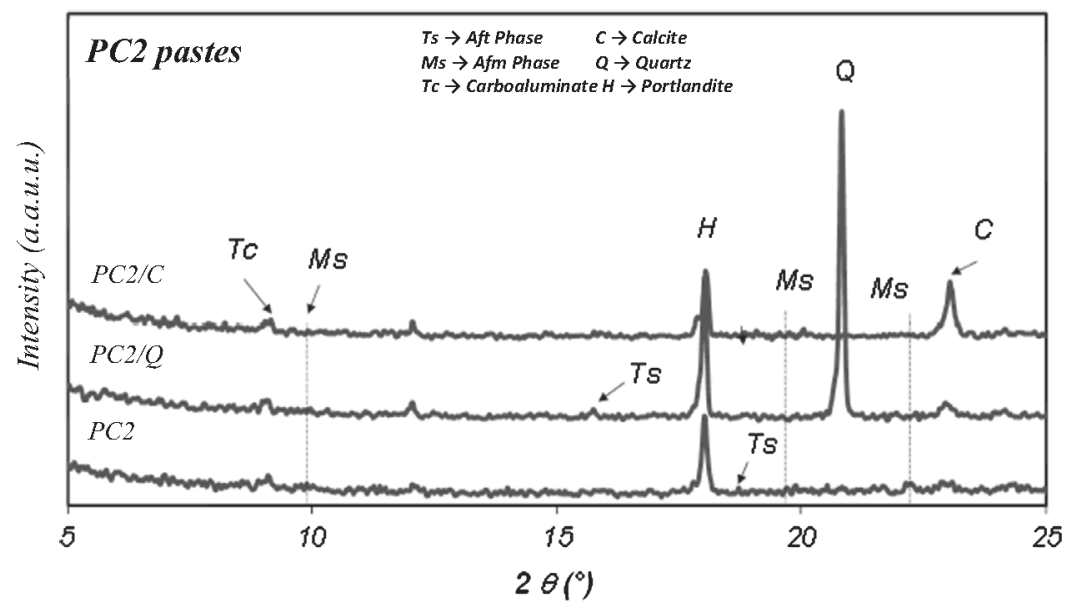

Fig. 11. XRD patterns for fresh PC2 pastes with and without fillerQ or C (60/40), during the latent period of hydration.

This very different behaviour of the two Portland cements in rheology test is due to:

(a) Their different mineralogical compositions and $\mathrm{Na}_{2} \mathrm{Oeq}(\%)$ contents very specially.

(b) Their different Frattini test results at all ages (Fig. 5).

(c) Their different water demand for normal consistency and setting times (Table 1 ).

(d) The different amount and type of hydration products generated when controlled rate rheological tests were conducted (Figs. 10 and 11).

(e) The different higher yield stress of PC1 than PC2 calculated by Casson model (Tables 3 and 4 ).

All these differences explain their different behaviours in rheology test. The explanation must lie either in the higher $\mathrm{C}_{3} \mathrm{~A}$ and $\mathrm{Na}_{2}$ Oeq. contents (\%) in $\mathrm{PC} 1$, the higher $\mathrm{C}_{3} \mathrm{~S}$ content (\%) in PC2 or any combination of the three. Nonetheless, the higher hydration rate of $\mathrm{C}_{3} \mathrm{~A}$ in $\mathrm{PC} 1$ must have played a lead role, but its greater $\mathrm{Na}_{2} \mathrm{Oeq}$. content (\%) holding priority always. Hence that fresh paste's "settability", with the resulting rotational consequences observed.

The zeta potential value for fresh cement paste was higher for PC1 than PC2 (Fig. 12). Those findings were closely related to the $\mathrm{pH}$ values obtained for the liquid phase of the respective pastes.
At all ages, fresh paste $\mathrm{PC} 1$ generated a more basic medium than fresh paste $P C 2$, which led to higher absolute zeta potential values, more negative in this case, due to the higher $\mathrm{Na}^{+}$and $\mathrm{K}^{+}$concentration in the liquid phase, in turn attributable once again to the higher $\mathrm{Na}_{2} \mathrm{O}_{\text {eq }}$.\%) content.

For that reason, the fresh PC1 pastes exhibited higher absolute zeta potential values. As a result, the individual particles were dispersed more widely due to the greater width of the double layer induced by the greater strength of the repulsion forces. In other words, the PC1 fresh paste system was moving into a more stable region, rendering its viscosity lower than in cement PC2, yet another consequence of the major differences in the mineralogical and chemical composition of the Portland cements studied, but above all, of its higher $\mathrm{Na}_{2} \mathrm{O}_{\text {eq }} \cdot(\%)$ content: $1.24 \%$ and 0.56 , respectively.

\subsubsection{Comparative study of $P C 1$ and $P C 2$ with $Q$ and $C$ fillers}

3.2.2.1. With $Q$ filler. When $Q$ filler was added to $P C 1$, shear strength rose at most of the singular points and where that was the case, the effect intensified when the replacement ratio was raised to $40 \%$. That increase in the apparent viscosity of the fresh paste induced by the inclusion of $Q$ filler was due to the larger number of $Q$ particles present in the paste (which, as wholly crystalline, were neither pozzolanic nor hydraulic). Their presence stimulated hydration of the fraction of PC1 directly $[1,23]$ and 

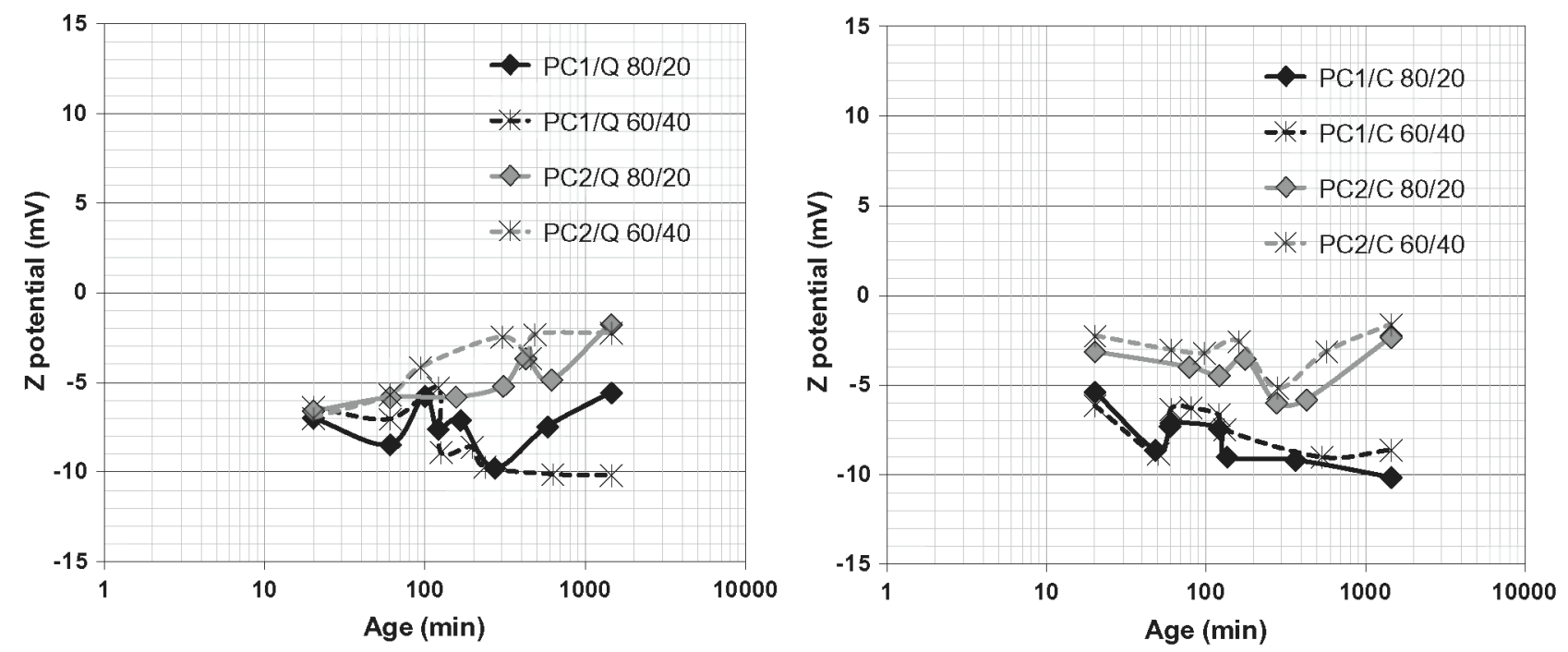

Fig. 12. Zeta potential of fresh $P C 1$ and $P C 2$ pastes with and without filler $Q$ or $C$, during the latent period of hydration.

non-directly [3] and with it the formation of the respective hydration products sourced primarily from $C_{3} A$, namely slow-forming ettringite, ett-If [25-28] and AFm (Fig. 10). These latter prompted a decline in fresh paste fluidity. The greater amount of the hydration products that could form, which would be proportional to the amount of hydration water available to the PC1 in the blend with Q filler (in this case, PC1/Q 60/40), the steeper would be the decline.

Furthermore, in fresh paste, these stimulating effects were curbed at some ages as a result of the physical dilution of PC1 by $Q$ filler. That would be supplemented by chemical dilution because what was in fact diluted was the liquid phase of the paste, and therefore its major constituents, portlandite and especially $\mathrm{Na}_{2}{ }^{-}$ Oeq. These phases were generated during initial PC1 hydration (for in such circumstances, paradoxically, the amounts of ett-rf and AFm formed by the 60\% PC1 in the blend should potentially be greater than the amounts of pure PC1: see Fig. 10). The inescapable result would be greater fresh paste viscosity. The foregoing is reinforced by the opposite rheological behaviour observed in families $P C 1 / Q$ and $P C 2 / Q$ at the same singular points.

- Viscosity was higher in the PC1/Q family fresh paste when the blend contained $40 \%$ filler (see Table 3 ). Conversely, in PC2/Q, viscosity was observed to be higher with a $20 \%$ replacement ratio.

- After the 10 s pause in each PC1/Q fresh paste, point $\mathrm{C} 2$ shear strength was greater in the two blends, $80 / 20$ and 60/40, than in pure $\mathrm{PC} 1$ (Table 3), whereas in $\mathrm{PC2}$, shear strength should have been and was greater in the $80 / 20$ blend only.

- Fresh paste shear strength at point $C_{1}$ was greater than at point $\mathrm{C}_{2}$ in the PC1 family, and vice versa in the PC2 family.

- Fresh paste shear strength at point $C_{3}$ was greater in PC1/Q than in pure $\mathrm{PC} 1$ and rose with the replacement ratio. In contrast, $\mathrm{PC} 2 / \mathrm{Q}$ strength at that point was lower than pure PC2 strength.

3.2.2.2. With $C$ filler. Lastly, all the Portland cements were blended with $C$ filler. An analysis of the respective yield stress values $\left(\sigma_{0}\right.$, Tables 3 and 4 ) showed, firstly, that the addition of $C$ filler induced greater hydration stimulation directly $[1,23]$, non-directly [3] and indirectly [24] (in the absence of pozzolanicity) in the PC1 with which it was blended, and in particular in its $\mathrm{C}_{3} \mathrm{~A}$ fraction. The effect was such that in PC1/C 80/20, yield stress was reached at a higher shear strength value. This pattern was not observed in
PC2 due to the total absence of $\mathrm{C}_{3} \mathrm{~A}$ in this cement, with a substantial weakening of the stimulus attributable to fraction $C$ filler. Under these circumstances, physical dilution prevailed over all other developments.

Moreover, when $C$ filler was added to $\mathrm{PC} 1$, shear strength rose at most of the singular points in the first CR cycle and where that was the case, the effect intensified when the replacement ratio was raised to $40 \%$. That increase in the apparent viscosity of the fresh paste induced by the inclusion of $C$ filler was due once again to the larger number of $C$ particles present in the paste. Their presence stimulated hydration of the fraction of PC1 directly $[1,23]$ and non-directly [3] as well as indirectly in the absence of preexisting pozzolanicity [24], with the concomitant formation of the respective hydration products characteristic of PC1, namely slow-forming ettringite, ett-lf [25-28], AFm and calcium tricarboaluminate hydrate (Figs. 10 and 11). These latter prompted a decline in fresh paste fluidity to the point of decomposition due to shear stress. The greater the amount of the hydration products that could form, which would be proportional to the amount of hydration water available to the PC1 in the blend with $C$ filler (in this case, PC1/C 60/40), the steeper would be the decline.

In all the fresh pastes containing $C$ filler, this stimulating effect prevailed over the physical dilution of the $P C$ by the $C$ filler and over the associated effect of the chemical dilution of the liquid phase of the paste and its main constituents, portlandite and $\mathrm{Na}_{2} \mathrm{Oeq}$. More specifically, the non-direct stimulation of hydration [3] prompted by $\mathrm{C}$ filler was favoured in PC2. That finding is closely related to the zeta potential findings for the fresh pastes from the onset of hydration through the end setting time (Fig. 12). In contrast, direct and indirect stimulation of hydration was favoured in PC1. More precisely, it cannot be contended that non-direct stimulation is not favoured by $\mathrm{C}$ filler in $\mathrm{PC} 1$, inasmuch as such stimulation was in fact present, given that the zeta potential rose as hydration progressed. Rather, the explanation may lie in that the $C_{3} A$ content in the blend may have been depleted because its hydration was stimulated much earlier via the direct and indirect routes.

\section{3. $X$-ray diffraction and $Z$ potential analysis}

The hydration compounds during the latent period of hydration are identified in the XRD patterns illustrated in Figs. 10 and 11 for PC1 and PC2 cements, respectively, and for $60 / 40$ blended cements containing $Q$ and $C$ crystalline mineral additions filler type. 
For $\mathrm{PC} 1$ and $\mathrm{PC} 2$ pastes with $\mathrm{Q}$ and $\mathrm{C}$ crystalline mineral additions filler type, the intensity of $\mathrm{CH}$ peak was stronger than the corresponding to $\mathrm{PC} 1$ and $\mathrm{PC} 2$ pastes. XRD results confirm the stimulation effect on the hydration reactions that has also been shown in the physical and rheological tests. On the other hand, the formation of the tri-substituted aluminum ferrite compounds was demonstrated (AFt: Ts or Tc), and its very early transformation to the mono-substituted aluminum ferrite compound phase (AFm: Ms) for cement based made on PC1. In the case of PC2 and PC2 blends, the practical absence of the mono- and tri-substituted particularly aluminum ferrite phases (AFt and AFm) was verified in correspondence with the absence of $C_{3} A$ in the $P C 2$.

At very early ages, Tc formation is especially interesting in blends with the filler $C$ having been formed from the $C_{3} A$ derived from the PC1. These compounds have been found previously in other experiments [1-4]. Similarly, the formation of carbonate hydrated calcium silicate (CS) has also been detected previously [1-3].

In both cases, irrespective of the filler used ( $Q$ or $C$ ), the deflocculating conditions in the PC1 cementitious system were more intense [20], since its zeta potential values exhibited higher absolute values throughout the hydration latency period (Fig. 12). For that reason, the fresh PC2 cements blended with either filler generated a more electrostatically stable and more viscous medium. That finding was clearly impacted by the alkalinity of the liquid phase of the paste and therefore by the amount of soluble $\mathrm{Na}_{2} \mathrm{O}$ and $\mathrm{K}_{2} \mathrm{O}$ present and of portlandite forming from its clinker.

An explanation can also be given for the higher apparent viscosity in general in the blends of both PCs with both percentages of both fillers (Tables 3 and 4 ) than in the pure PCs. These blends were closer to the isoelectric point at which the charge distribution of any solution is nil [7] and tends toward electrostatic equilibrium. That favours a higher fresh paste viscosity.

In addition, both fillers acted as nucleation-precipitation sites [3], respectively, for portlandite crystals, stimulating hydration non-directly $[2,3]$. C filler exhibited higher performance in this respect, adopting the role of "seed crystal" in portlandite crystal precipitation, although the epitaxial phenomenon is absent $[29,30]$.

\section{Conclusions}

1. Very early-age hydration in both Portland cements studied was stimulated directly, non-directly and indirectly by the presence of mineral fillers, although only $C$ filler prompted indirect stimulation (see conclusion 4 for a fuller discussion). Stimulation intensified with the percentage of Portland cement replaced by filler, without prejudice to the effect associated with the physical dilution of the cement and the liquid phase in its fresh paste, which prevails when stimulation weakens.

2. Q filler has strangely fulfilled the Frattini test at the age of 20 minutes when it was mixed with PC1 in the 60/40 blend ratio. This result is not real, it was fictitious and it is a "false positive" result, which has been duly justified, because the $Q$ filler does not have any pozzolanic characteristic because it is a totally crystalline a-quartz.

3. The viscosity of any Portland cement fresh paste and their yield stress depends on:

- on the qualitative and quantitative mineralogical and chemical composition, $\mathrm{Na}_{2} \mathrm{Oeq} .(\%)$ content especially of the cement, i.e., the alkaline element content in the liquid phase of their fresh paste, and

- on the amount and types of hydrated compounds generated during the hydration latency period, when the fresh paste is fluid.
4. Further to conclusion 3, the inclusion of crystalline fillers in Portland cement induces greater viscosity in its fresh paste due to the quicker formation of more hydration products (such as ettringite, AFm and $\mathrm{C}-\mathrm{S}-\mathrm{H}$ gels) due to the stimulation referred to in conclusion 1 . In some cases, that increase in product formation is further favoured by the chemical dilution affecting the liquid phase of the blend, but not by the effect of the physical dilution of the Portland cement present in the fresh paste, for in that case stimulation would be attenuated Nonetheless, the equilibrium between those effects is reached when the 'boundary' replacement ratio is used.

5. The three routes for hydration stimulation induced by $Q$ and $C$ fillers in Portland cement have a greater or lesser impact depending on the composition of the cement itself, as well as on the siliceous or calcareous nature of the filler. Direct hydration stimulation prevails when the Portland cement at issue has a high aluminate phase, such as $C_{3} A(\%)$. The non-direct route predominates when the aluminate phase content in the Portland cement is low, i.e., when its silicate phase content is high, $\mathrm{C}_{3} \mathrm{~S}$ especially. Lastly, indirect stimulation in the absence of pozzolanicity is present only where the $C_{3} A$ content is high and only when calcareous filler is used.

\section{References}

[1] V. Rahhal, R. Talero, Early hydration of Portland cement with crystalline mineral additions, Cem. Concr. Res. 5 (7) (2005) 1285-1291.

[2] V. Rahhal, V. Bonavetti, A. Delgado, C. Pedrajas, R. Talero, Scheme of the Portland cement hydration with crystalline mineral admixtures and other aspects, Silicates Ind. 74 (11-12) (2009) 347-352.

[3] V. Rahhal, V. Bonavetti, L. Trusilewicz, C. Pedrajas, R. Talero, Role of the filler on Portland cement hydration at early ages, Constr. Build. Mater. 27 (1) (2012) $82-90$.

[4] J. Pera, S. Husson, B. Guilhot, Influence of finely ground limestone on cement hydration, Cem. Concr. Compos. 21 (1999) 99-105.

[5] R. Talero, V. Rahhal, Calorimetric comparison of Portland cement containing silica fume and metakaolin: is silica fume, like metakaolin, characterized by pozzolanic activity that is more specific than generic?, J Therm. Anal. Cal. 96 (2) (2009) 383-393.

[6] V. Rahhal, R. Talero, Fast physics-chemical characterization of fly ash, J. Therm. Anal. Cal. 96 (2) (2009) 369-374.

[7] Talero R., Pedrajas C, Rahhal V. Performance of fresh Portland cement pastes. Determination of some specific rheological parameters. Rheology-New Concepts, Applications and Methods. In Tech, Rajkumar Durauraj, 2013.

[8] K. Vance, A. Arora, G. Sant, N. Neithalath, Rheological evaluations of interground and blended cement-limestone suspensions, Constr. Build. Mater. 79 (2015) 65-72.

[9] C.F. Ferraris, K.H. Obla, R. Hill, The influence of mineral admixtures on the rheology of cement paste and concrete, Cem. Concr. Res. 31 (2) (2001) 245255.

[10] Kubens S, Wallevik O. Interaction of cement and admixtures-the influence of cement deliveries on rheological properties, Proceedings of the 16th Bausil, Weimar, Germany, 2006

[11] C. Pedrajas, V. Rahhal, R. Talero, Determination of characteristic rheological parameters in Portland cement pastes, Constr. Builld. Mater. 51 (2014) 484491.

[12] Instrucción para la Recepción de Cementos RC-16 (R.D. 256/2016 de 10 de junio; BOE núm. 153 del 25 de junio de 2016), Cement Acceptance Instruction RC-08. Spanish Association for Standardization and Certification - AENOR, Madrid, Spain, 2008

[13] EN 197-1:2000 Standard. Cement. Part 1: Composition, specifications and conformity criteria for common cements. AENOR.

[14] ASTM C 778-92a Standard. Standard Specification for Standard Sand. Annual Book of ASTM Standars, Section 4, Vol. 04.01 Cement; Lime; Gypsum, pp. 329331.

[15] ASTM C 595M Standard: Standard Specification for Blended Hydraulic Cements.- Annual Book of ASTM Standars, Section 4, Vol. 04.01 Cement; Lime; Gypsum, pp. 291-296.

[16] EN 197-3:2012 Standard. Methods of testing cement. Part 3. Times of setting and volume stability determinations (Le Chatelier's needles). AENOR.

[17] EN 196-5:2005 Standard. Methods for Testing Cement. Part 5: Pozzolanicity Test for Pozzolanic Cements. AENOR.

[18] A. Albertazzi, E. Rastelli, Evaluation of the thixotropy and yield stress of industrial ceramic slips using a torque-type viscometer, Ceramica Acta $9(4)$ (1997) 5-11.

[19] Pedrajas C. (2015). Rheological behavior of fresh Portland cement pastes with natural and artificial pozzolanic additions and non-pozzolanic. PhD thesis, Castilla-La Mancha University, 8th feb. 2016. 
[20] Moreno R. Reología de Suspensiones Cerámicas. Biblioteca de Ciencias, 17. Consejo Superior de Investigaciones Científicas. Madrid; (Spain) 2005. (in Spanish).

[21] Melgarejo JC (editor) Atlas de Asociaciones Minerales en Lámina Delgada. Universidad de Barcelona, Fundación Folch, Reedición: Publicaciones UB., vols. I and II. Publicaciones de la Univ. de Barcelona, Adolfo Florensa, s/n, 08028Barcelona; (Spain) 2003. (in Spanish).

[22] F. Bastida, Geología: Una visión moderna de las ciencias de la tierra, vol. I. Ediciones Trea, SL, María González la Pondala, 98, Nave D, 33393-Gijón (Spain), 2005, (in Spanish).

[23] V. Rahhal, Characterization of pozzolanic additions by conduction calorimetry. Ph.D. thesis, Polytechnic University of Madrid, E.T.S. Ings. Caminos, Canales y Puertos, 12th dec. 2002

[24] R. Talero, Performance of silicic pozzolans and Portland cements in their behaviour in front of gypsum attack as determined by ASTM C452-68, Mater. Constr. 63 (310) (2013) 159-193.

[25] R. Talero, Kinetochemical and morphological differentiation of ettringites by the Le Chatelier-Ansttet test, Cem. Concr. Res. 32 (2002) 707-717.
[26] R. Talero, Kinetic and morphological differentiation of ettringites by metakaolin, Portland cements and ASTM C 452-68 test Part I: Kinetic differentiation, Mater. Constr. 58 (292) (2008) 45-68.

[27] R. Talero Kinetic and morphological differentiation of ettringites by metakaolin, Portland cements and ASTM C 452-68 test. Part II: Morphological differentiation by SEM and XRD analysis Mater. Constr. 59 29320091734 .

[28] R. Talero, Expansive Synergic Effect of ettringite from pozzolan (metakaolin) and from OPC, co-precipitating in a common plaster-bearing solution. Part II: Fundamentals, explanation and justification, Constr. Buîld. Mater. 25 (3) (2011) 1739-1758.

[29] E N Maslen, VA Streltsov, N R Streltsova, N Ishizawa, Electron density and optical anisotropy in rhombohedral carbonates. III. Synchrotron X-ray studies of $\mathrm{CaCO}_{3}, \mathrm{MgCO}_{3}$ and $\mathrm{MnCO}_{3}$, Acta Crystallogr. A B51 (6) (1995) 929-939.

[30] H.E. Petch, The hydrogen positions in portlandite, $\mathrm{Ca}(\mathrm{OH})_{2}$, as indicated by the electron distribution, Acta Crystallogr. A 14 (9) (1961) 950-957. 